Session 3261 Ethics \& HSS in Engineering

\title{
Addressing the Liberal Arts in a Core Engineering Class: Theology, Philosophy, Social Ethics, and The Second Law of Thermodynamics
}

\author{
Dr. David W. Shaw and Dr. James S. Gidley \\ Department of Engineering, Geneva College, Beaver Falls, PA
}

Introduction

Can an engineering professor address theological, philosophical, and social issues in a core engineering class in a way that is relevant to the core content of the class? Our answer is yes. We have been addressing such issues for more than a decade in an introductory thermodynamics class required of all students in the general engineering program at Geneva College. Our primary vehicle for doing this has been a term paper assignment requiring the students to relate the second law of thermodynamics to issues that are ordinarily the domain of the liberal arts faculty. While the particular contours of the assignment are unique to the mission of Geneva, the authors believe that their approach is adaptable to a wide variety of institutions.

The first author developed a term paper assignment in 1991 requiring students to "consider the development of technology in terms of entropy and the second law of thermodynamics" in the light of biblical teaching and requiring them to consider how their conclusions would "influence their career choice and professional activities." The second author began teaching the course in 1998 and initially continued with essentially the same assignment. He modified it in 2000, focusing the students somewhat more narrowly on five specific theological and philosophical positions that can be or have been taken regarding the second law. In 2003, he modified the assignment again, requiring the students "to formulate and defend a thesis that relates entropy or the increase of entropy principle to one or more of the concepts" given in the following list: creation, stewardship of creation, the fall, evolution, pollution, and eschatology. The core objective of the assignment has remained the same, and it has become an established, successful feature in the engineering program at Geneva College.

Writing in Technical Courses - A Brief Review of the Literature

Several papers related to our work have been published in the Journal of Engineering Education from 1993 to the present. The most directly relevant work is a Writing-Across-the-Curriculum approach used at Utah State University. ${ }^{1}$ The WAC approach linked a required engineering course with a required writing course. Writing assignments included "societal impacts of environmental racism" and "the cost and ethics of clean-up of hazardous waste sites." 
Most other studies involved technical writing, ${ }^{2,3}$ writing-to-learn/incidental writing, ${ }^{4,5}$ or some combination of these. ${ }^{6}$ All shared the goal of reinforcing writing skills throughout the educational process by continued practice, but they differed in the types of assignments, the complexity of interaction between departments, and the formality of the writing assignments.

Our approach has been unique in several ways. Our writing assignment is part of a technical course, Engineering Thermodynamics, required of all engineering majors, but it is more typical of writing assignments given in liberal arts courses. The linkage between the technical and the social aspects is very clear and direct, since the assignment is set in the context of the technical course, but assumes a background in the liberal arts. As will be discussed later, many students actually see the connection and use material from Bible and humanities courses.

The Assignment as the Expression of the Mission of Geneva College and as a Fulfillment of ABET Criteria

Our approach is a direct result of the unique mission of Geneva College. The mission of Geneva College is directly supportive of efforts to integrate scientific and professional studies with the liberal arts and the Christian faith. The current version of the mission statement is as follows:

The mission of Geneva College is to glorify God by educating and ministering to a diverse community of students for the purpose of developing servant-leaders, transforming society for the kingdom of Christ. We accomplish this through biblically based programs and services marked by excellence and anchored by the historic, evangelical, and Reformed Christian faith. The curriculum is rooted in the liberal arts and sciences, vocationally focused and delivered through traditional and specialized programs.

The Engineering Department developed its own mission statement and eight objectives in the process of complying with the ABET 2000 Criteria:

The mission of the Engineering Department is to educate and minister to a diverse community of students for the purpose of developing engineering professionals who will see their careers as a calling from God in which they may glorify Him and love their neighbors, providing excellent engineering services in an environment of technological change.

Objective 1: To develop in students a Biblical view of the world, their lives, and their professions, helping them to see their professions as a calling from God in which they may serve Him and in so doing may do good to others and have a transforming effect on society.

The faculty of the College are also strongly encouraged to pursue the integration of faith and learning within their own disciplines. Many students come to the College particularly to be educated in such an environment. Encouraging students to think about the connections between thermodynamics, social, ethical and philosophical issues, and the Christian faith is a direct outgrowth of the unique mission and environment of Geneva College. 
While public and nonreligious private universities have different missions and have no particular zeal to encourage Christian faith, the authors believe that most institutions have some element in their mission that supports integrative efforts. For example, Penn State University's mission speaks of "integrated, high-quality programs,", Carnegie Mellon University speaks of "commitment to ... ethical behavior,", and the University of Utah says, "The right of free inquiry is zealously preserved; diversity is encouraged and respected; critical examination and creativity are promoted; and intellectual integrity and social responsibility are fostered."9 While these statements are vague and general, they testify to a belief that the university really is a place where the unity of knowledge is professed and that there are linkages between the sciences and the liberal arts. The second law of thermodynamics has long been explored for just such linkages to social science and the liberal arts, without particular faith-commitments explicitly in view. $^{10}$

Our approach also helps to satisfy ABET Criterion 3, parts g and h: ${ }^{11}$

Criterion 3. Program Outcomes and Assessment

Engineering programs must demonstrate that their graduates have:

(g) an ability to communicate effectively

(h) the broad education necessary to understand the impact of engineering solutions in a global and societal context

We do so in a way that fits naturally within the goals of the College and the Engineering Department. We reinforce the mechanics of writing well, the connection of the liberal arts to the practice of engineering, and the worldview leading to its practice.

The Origin of the Assignment

The first author taught Thermodynamics (MEE 310, which became EGR 314 in 1993) from 1990 to 1997. As the course was adapted to provide an integrated rather than sequential coverage of the first and second laws and was adjusted to fit into an engineering curriculum being redesigned to meet the ABET criteria for general engineering, we thought it was important to be more intentional about integrating the objectives underlying ABET criterion $3 \mathrm{~g}$, and $\mathrm{h}$ into appropriate engineering courses. Thermodynamics seemed a logical place to attempt this, particularly with respect to the second law. These changes meshed well with a more modern approach to second law analysis, which was becoming a larger part of the course.

The writing assignment was first used in the fall of 1991, and remained essentially unchanged through the fall of 1999. (The course is taught once a year.) The basic statement describing the paper was in three parts.

Consider the development of technology in terms of entropy and the second law of thermodynamics. What are the increases in entropy (disorder) which come 
about to make up for the increases in order (for example, greater life expectancy and a higher standard of living) which the technology user experiences?

In light of the dominion mandate (for example, Genesis 1:28), what do you believe to be a practical Christian approach to the advance of technology and its effect on the entropy of the universe? Give the biblical basis for your view.

How does or should this influence your career choice and professional activities? Give clear and specific examples of how the approach you have outlined does or could find application.

Students were required to write a clearly reasoned, logically defended and well-supported essay with appropriate references. The assignment was distributed early in the semester and due approximately five to seven weeks into the semester. As the course structure changed it became possible to move the assignment to the earlier due date.

The three main questions of the assignment move through three basic stages, providing a clear outline for student research and a framework for increasing understanding. The first question is descriptive and attempts to root the student in a basic understanding of the second law. The second leads the student to think about the normative, the standards that govern human behavior. The third is practical application based on the previous answers.

In the first year of the assignment it became clear upon reading the papers that the students did not really think that an engineering professor would require a significant non-technical research paper. Many papers lacked a clear research base and consisted mostly of unsupported statements of opinion. A more careful definition of the expectations of a formal research paper in future years took only a few minutes of class time but greatly improved the final products. The authors also suspect that word-of-mouth communication that the instructor was serious about this assignment also contributed to increased quality. Even in the weakest papers, most students articulated one of four worldviews that connected to their practical applications, summarized by the authors as:

1. Transformer - God is active in the world, and expects us to be active too.

2. Reactor - If I don't do anything "bad," God will get my attention if he wants me to make changes.

3. Agnostic/Deist - It doesn't matter if there is a God, or God is not very involved at the moment. Just do what is "right."

4. Cyclic-Life goes on, no matter what we do. The universe is cyclic.

The practical applications ranged from those who adopted anti-technology views, often inspired by Jeremy Rifkin, ${ }^{12}$ to those who promoted technology at nearly any cost. Most adopted a position that might best be described as stewardship ethics. That is, the earth is entrusted to us, with the expectation that we will use it and develop technology that lovingly serves the needs of humans. ${ }^{13}$ 
Some of the most interesting outcomes of this assignment have been

1. Clear statements by most students that this assignment has affected their view of career and vocation. Some of these statements were in the papers themselves, while others are overheard in discussions in the hallway, in cars on the way to professional meetings, etc.

2. Lots of interesting titles, showing a great deal of creativity among these third-year engineering students.

3. Many direct references to lectures and notes from the required Bible and Humanities courses.

4. Evidence of students reading books and journals that would not normally be recreational reading material for third-year engineering students, even material by scientists and philosophers such as Stephen Hawking, Roger Penrose, and Rousas Rushdoony.

5. Lots of new reading material for the instructor, as students uncovered material relating the second law of thermodynamics to fields such as economics, sociology, and appropriate technology.

6. Evidence of creativity in writing style, ranging from political satire to the use of poetry to set the tone of the paper.

After the papers were graded and returned, part of a lecture was used to summarize results and challenge students to think further about these issues. It was usually possible to point out the different worldviews found in the papers and to make connections to material from required courses in Bible and humanities.

Although the second law is an interesting jumping-off point for discussions about stewardship and environmental issues, most students rightly noted that concerns about the heat death of the universe were not really the immediate concern of engineers. There are many environmental and stewardship concerns that demand the engineer's attention on a time scale of tens of years rather than of millions of years. This was an encouraging result, since the students did not just blindly follow the outline implied in the stated assignment but actually extended the discussion to come up with a balanced approach to their careers.

\section{Statistical Evaluation of Student Perceptions}

We have also assessed the impact of the assignment quantitatively by analyzing data from student evaluations of the course compared to evaluations of other courses. Throughout the period 1990-1991 to 1998-1999, Geneva College used an in-house evaluation instrument that contained a single question (number 12) asking students about the integration of the course's subject matter with the Christian faith. While this question is focused specifically on the Christian faith, we believe that it provides some indication of the degree to which the course integrates technical content with the broader issues of the liberal arts. Since our evaluation instruments have not included a question directed towards the integration of science, engineering, and the liberal arts, question 12 is as close as we can come to assessing that integration in this retrospective analysis.

The first two rows of Table 1 show the results of the evaluation for MEE 310 before and after the introduction of the assignment. Other courses serve as controls in two directions. EGR 211, 
Solid Mechanics, EGR 214, Dynamics, and EGR 315, Transport Processes, are highly technical courses in which the authors made little or no attempt to relate the subject matter explicitly to the

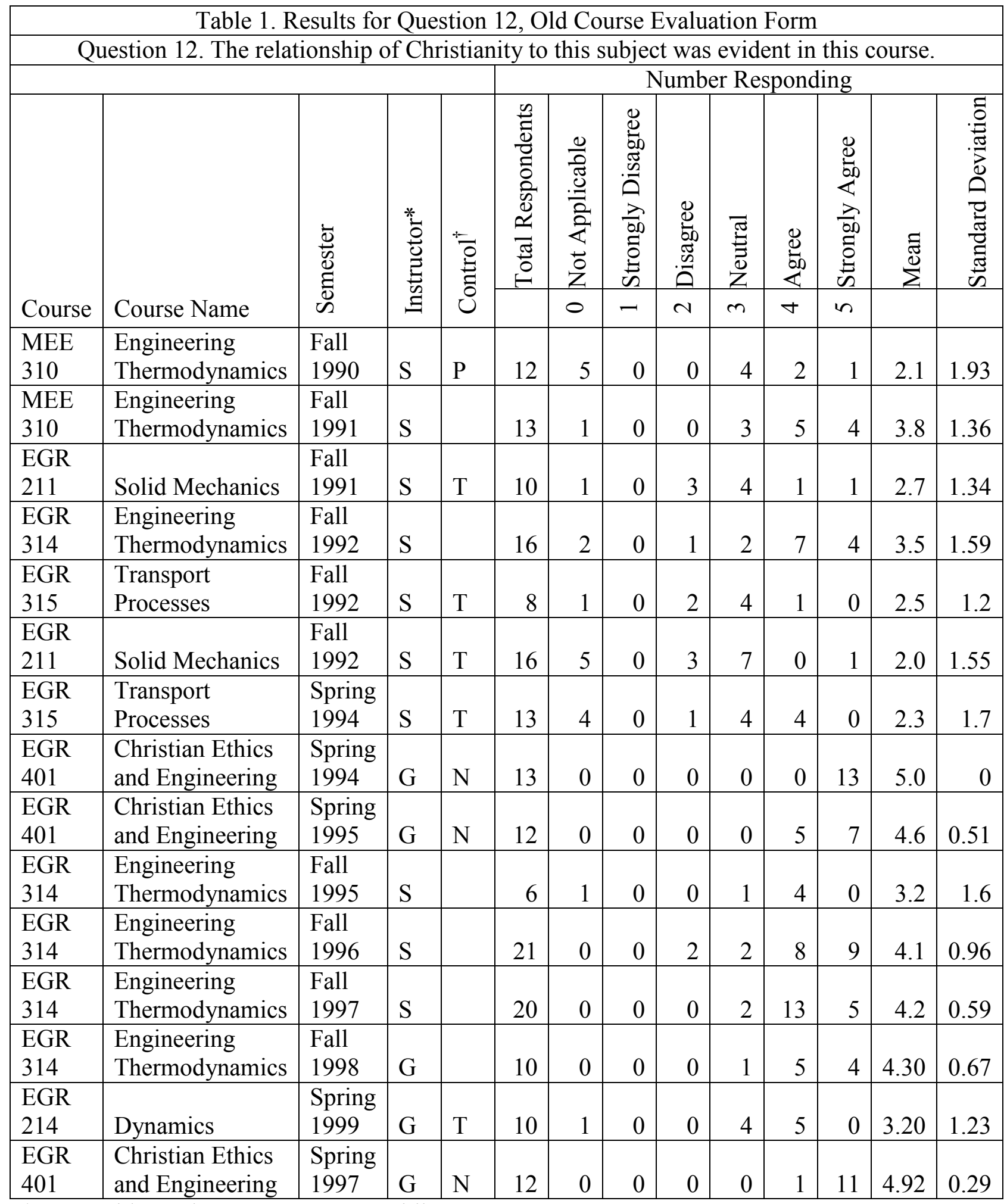

*S = David W. Shaw; $\mathrm{G}=$ James S. Gidley

${ }^{\dagger} \mathrm{P}=$ Pre-Assignment Course, $\mathrm{T}=$ Technical Course, $\mathrm{N}=$ Non-technical Course

"Proceedings of the 2004 American Society for Engineering Education 
Christian faith or to social or ethical issues. Therefore, we would expect the mean response on question 12 to be significantly lower for these courses than the mean response in MEE 310/EGR 314. In EGR 401, Christian Ethics in Engineering, the second author refers to the Bible and Christian faith in every class meeting. Therefore we would expect the mean response on question 12 to be significantly higher for EGR 401.

Because of the small sample size and the presence of zeroes in some of the response categories, it is not appropriate to use a chi-square test to compare the responses. Instead, we used the nonparametric Wilcoxon Two-Sample Test ${ }^{14}$ (one-tailed test) to compare mean responses. We treated the "not applicable" response as a meaningful response with a numerical value of zero. We believe that by it the student professes to believe that the subject matter of the course has no relation to the Christian faith. Because we believe that thermodynamics is related to the Christian faith, we see the reduction of the number of "not applicable" responses as a real pedagogical success.

The first Wilcoxon test comparison (Table 2) is the "before-and-after" comparison, because the assignment was introduced in 1991. We conclude from this result that the assignment made a statistically significant difference in student perceptions. When comparing MEE 310/EGR 314 to the technical control courses EGR 211, EGR 214, and EGR 315, the same result is typically found: the students perceive thermodynamics to be more relevant to the Christian faith than the courses covered in a purely technical manner. On the other hand, comparisons with EGR 401 typically show the expected result that students see ethics to be more relevant to the Christian faith than thermodynamics.

\begin{tabular}{|c|c|c|c|c|}
\hline \multicolumn{2}{|c|}{ Table 2. Results of Wilcoxon Two-Sample Tests, Data from Old Evaluation Form } \\
\hline Test Course & Control Course & Expected Result & Actual Result & $\begin{array}{c}\text { Significance } \\
\text { Level }\end{array}$ \\
\hline MEE 310 1991 & MEE 310 1990 & Test $>$ Control & Test $>$ Control & $2.5 \%$ \\
\hline MEE 310 1991 & EGR 211 1991 & Test $>$ Control & Test $>$ Control & $2.5 \%$ \\
\hline EGR 314 1992 & EGR 315 1992 & Test $>$ Control & Test $>$ Control & $2.5 \%$ \\
\hline EGR 314 1995 & EGR 315 1994 & Test $>$ Control & Test $>$ Control & insignificant \\
\hline EGR 314 1996 & EGR 315 1994 & Test $>$ Control & Test $>$ Control & $0.059 \%$ \\
\hline EGR 314 1997 & EGR 315 1994 & Test $>$ Control & Test $>$ Control & $2.5 \%$ \\
\hline EGR 314 1995 & EGR 401 1995 & Control $>$ Test & Control $>$ Test & $1 \%$ \\
\hline EGR 314 1996 & EGR 401 1995 & Control $>$ Test & Control $>$ Test & insignificant \\
\hline EGR 314 1997 & EGR 401 1997 & Control $>$ Test & Control $>$ Test & $0.1 \%$ \\
\hline EGR 314 1998 & EGR 214 1999 & Test $>$ Control & Test $>$ Control & $2.5 \%$ \\
\hline EGR 314 1998 & EGR 401 1997 & Control $>$ Test & Control $>$ Test & $2.5 \%$ \\
\hline
\end{tabular}

The Evolution of the Assignment

The second author took over the teaching of the course in the Fall of 1998 and continued the assignment in essentially the same form for the next two course offerings (Fall 1998 and Fall 1999). One student commented on the 1998 course evaluation: "... I really enjoyed the Entropy paper. It stimulated my thinking of Engineering in relation to God \& the world."

\footnotetext{
"Proceedings of the 2004 American Society for Engineering Education Annual Conference \& Exposition Copyright (C) 2004, American Society for Engineering Education”
} 
The results of student evaluations and the statistical tests show the same kinds of significant differences in student perception as had occurred when the first author was teaching the course. Therefore we conclude that the difference in perception was not idiosyncratic to the particular instructor.

In reading the papers during these two semesters, the second author noticed that many students had difficulty focusing their ideas around a clear theme or thesis. In addition, some students attempted to write on such a broad topic that meaningful conclusions were virtually impossible within the limits of a short paper. As an attempt to focus students on a clear thesis, to encourage them to utilize evidence and arguments in favor or against the thesis, and for other reasons, the second author modified the assignment in Fall Semester of 2000 by providing five position statements (themes) from which the students were to choose:

1. The increase of entropy principle reflects the way God created the world; that is, it has been a characteristic of creation from the beginning, even before the Fall.

2. The increase of entropy principle reflects the curse that God placed upon the creation after the Fall (see Genesis 3:17-19); that is, before the Fall, the entropy of the universe did not increase.

3. The increase of entropy principle implies that the universe is becoming more disorderly. The theory of evolution implies that the universe is becoming more orderly. Therefore, the theory of evolution must be false because it contradicts the second law of thermodynamics.

4. Since all real processes increase the entropy of the universe, the more rapidly that technology advances, the more rapidly the entropy of the universe is increased. Increasing entropy is associated with the waste of resources and the production of pollution. Therefore, technological advance should be restrained or limited.

5. There's plenty of energy available in the universe, and human activities don't increase entropy significantly. God gave us the creation to use and enjoy. Therefore, no restraints or limitations should be placed on technology.

The five themes were developed as a crystallization of some of themes that are present in the literature on the broader implications of the second law and of themes that students had developed in past years. Some of the themes are commonly espoused by evangelical Protestants, from whom Geneva College draws a large part of its student body. Theme 2 is often stated by evangelical leaders as an evidence of the radical effects of the Fall, the entrance of sin into the world by the temptation and sin of Adam and Eve. ${ }^{15,16,17}$ Theme 1, essentially the denial of theme 2, is held by Gary North, ${ }^{18}$ who nevertheless holds that the effects of the second law changed after the Fall. Theme 3 is a favorite of young-earth creationists, ${ }^{16,19}$ who compose about half of the student body at Geneva currently, who often take it as an unanswerable refutation of evolution. Theme 4 in some form is espoused by Rifkin, ${ }^{12}$ and theme 5, essentially the denial of theme 4 , is held by North, ${ }^{18}$ who nevertheless places ethical limits on technology. 
The new form of the assignment required the students to defend or refute the position statement chosen, or to partially defend it and partially refute it. The second author also devoted a lecture to introducing these themes in a general way and some of the implications of them. This was intended to help students to see some of the strengths and weaknesses of the themes and to think about what kind of evidence and arguments would be effective in defending or refuting them.

The second author continued the assignment in essentially this form for three semesters (Fall 2000 to Fall 2002). Student perceptions remained similar to 1997-1998. In 2002 one student commented, "I really appreciated how much emphisis [sic] was placed on understanding thermodynamics in relation to the Christian walk. I wish more course [sic] provided that kind of link to our faith."

By 2001, Geneva was using a new course evaluation instrument, developed by the IDEA (Individual Development \& Educational Assessment) Center based at Kansas State University. The instrument allows Geneva to compare course evaluation results with national norms, but we will focus here on one of six questions unique to Geneva, which evaluate the integration of faith and learning (Table 3). This question is the most similar to question 12 on the old course evaluation form and is again our closest approach to assessing the integration of science, engineering, and the liberal arts in a retrospective analysis. The new evaluation form does not permit the "not applicable" response. Presumably a student believing that a question is not applicable to a course could omit responding to that question, and so we have shown the number

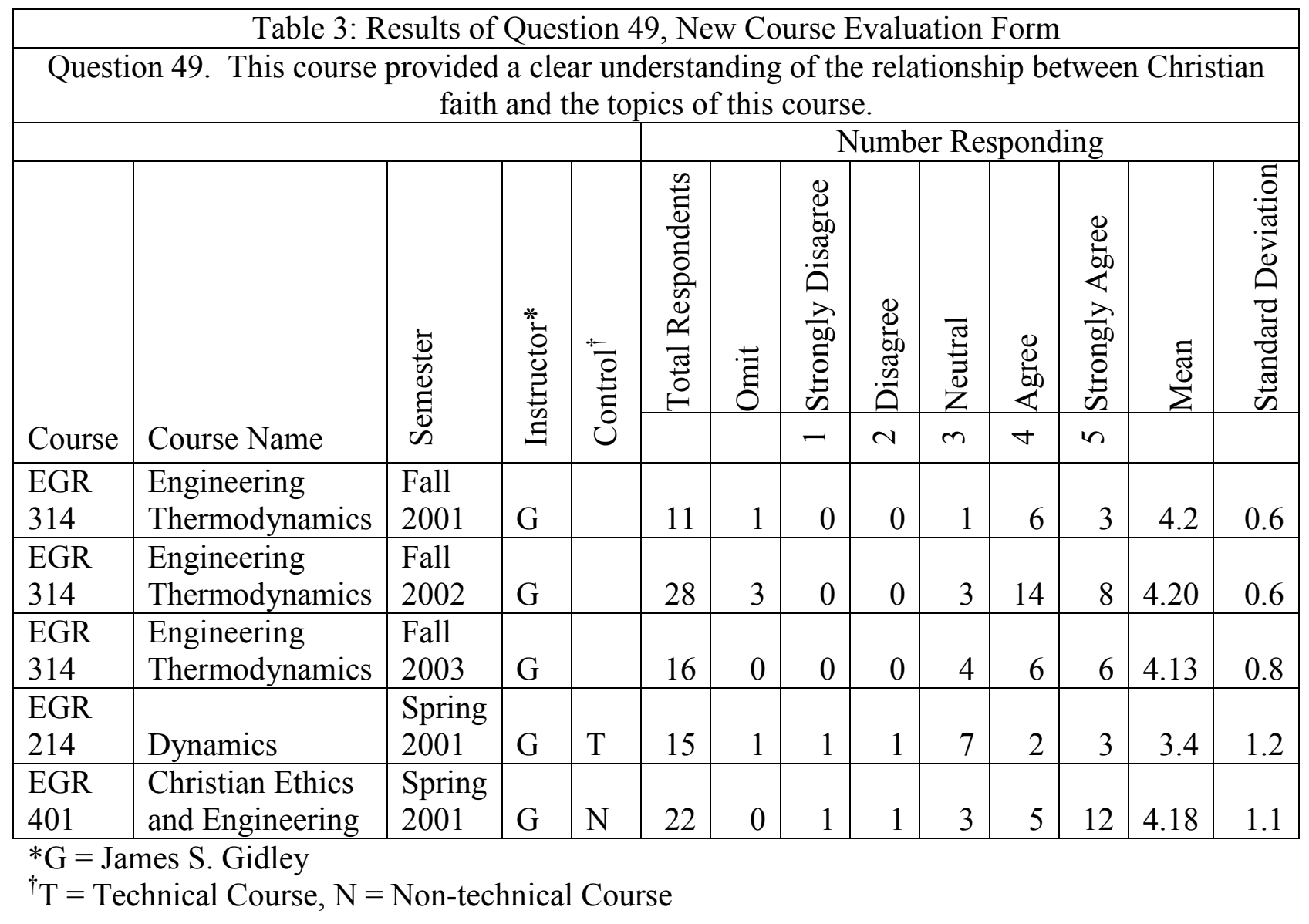

"Proceedings of the 2004 American Society for Engineering Education 
of omissions in the table. However, there could be other reasons for omissions, and so we have not included the omissions in the statistical tests.

Again, EGR 214 serves as a control course that had little or no non-technical content, while EGR 401 serves as a control with predominantly non-technical content. Wilcoxon two-sample test comparisons were made using the 2002 offering of EGR 314, since it had the larger sample size, and the distribution of responses in 2001 is quite similar in any case. The students still perceive a greater relevance of thermodynamics to the Christian faith than other technical subject matter (Table 4), but the comparison with EGR 401 shows an unexpected result, namely, that in 2002 the students actually perceived a slightly greater relevance of thermodynamics to the Christian faith than the students of ethics did in 2001, though the difference is not statistically significant. As can be seen by comparing Tables 3 and 1, this result is largely due to a downward shift in the mean response in EGR 401.

Table 4. Results of Wilcoxon Two-Sample Tests, Data from New Evaluation Form

\begin{tabular}{|c|c|c|c|c|}
\hline Test Course & Control Course & Expected Result & Actual Result & $\begin{array}{c}\text { Significance } \\
\text { Level }\end{array}$ \\
\hline EGR 314 2002 & EGR 214 2001 & Test $>$ Control & Test $>$ Control & $0.85 \%$ \\
\hline EGR 314 2002 & EGR 401 2001 & Control $>$ Test & Test $>$ Control & insignificant \\
\hline EGR 314 2003 & EGR 214 2001 & Test $>$ Control & Test $>$ Control & $5 \%$ \\
\hline EGR 314 2003 & EGR 401 2001 & Control $>$ Test & Control $>$ Test & insignificant \\
\hline
\end{tabular}

The second author subjectively concluded that the form of the assignment did not substantially improve the students' ability to focus their thoughts or to handle evidence and arguments effectively. In addition, the 2002 student evaluations for the first time included some negative comments about the assignment. One student said, "... The entropy paper was a bit confusing how it was worded. I believe I could have done better if I understood the assignment more clearly ...". Another said, "Of all the research papers I have written this is the first instructor that graded on whether you agreed with his position. To me this is intellectually disingenuous." The second author has made known his views on themes 1,2, and 3, and so the student comment most likely refers to these.

The authors are pleased with any student who can both spell and use the word "disingenuous" correctly. However, the comment raised an important question. The authors, both creationists, nevertheless regard theme 3 to be based on a misunderstanding of the second law of thermodynamics, and a quite basic misunderstanding at that. The second law does not require that the entropy of an open system such as the biosphere should always increase. Also, the argument of theme 3 assumes that the evolution of new species must be associated with a decrease of entropy in the biosphere. We regard this as problematic; to prove it would require careful definition of the entropy of living organisms and the changes of entropy brought about by the evolutionary differentiation of species. Then the definitions would have to be applied quantitatively to specific cases of species differentiation. The authors have never encountered such calculations showing that evolution actually decreases entropy, and we regard theme 3 to be an unproven and perhaps unprovable assertion. 
Likewise, theme 2 rests on the logical fallacy of equivocation: An increase of entropy means an increase of disorder; the entrance of sin into the world introduced disorder into creation; therefore, the increase of entropy began when sin entered into the world. Obviously the physical disorder of entropy is not the same thing as the moral disorder introduced by the Fall. Also, theme 2 fails to take into account the physical characteristics of an isentropic universe. As a single example, an isentropic universe cannot contain heat transfers over a finite temperature difference. This would preclude the shining of stars, clearly present before the Fall in the Biblical account.

Since logical fallacies and/or misunderstanding of the second law of thermodynamics are bound up with taking positions such as those expressed in themes 2 and 3, does a low grade on a paper defending them stem from the instructor's prejudice against these themes or from the errors in logic and/or the misunderstanding of the second law exhibited by the paper?

To help students to understand this, the second author modified the assignment again in the Fall of 2003. This time the author required the students to formulate their own thesis statements relating one or more of the following six concepts to entropy or the increase of entropy principle: creation (see Genesis 1-2), stewardship of creation, the Fall (see Genesis 3), evolution, pollution, or eschatology (the doctrine of last things). Another important modification of the assignment was to require a proposal stating the thesis to be defended and listing several references to be used, followed by the full paper two weeks later. The two-stage process allowed the instructor to interact with students in the process of developing their papers. Both at the time of the assignment and during the interaction period, the instructor gave students handouts explicitly raising issues regarding logical fallacies and misunderstandings of the second law.

The students' theses fell into five general categories (Table 5).

\begin{tabular}{|c|c|}
\hline Topic & Number of Students \\
\hline Creation, Evolution, and the Second Law & 9 \\
\hline Entropy and the Fall & 3 \\
\hline Entropy, Time, and Eschatology & 2 \\
\hline Entropy and Pollution & 2 \\
\hline Entropy and Stewardship of Creation & 1 \\
\hline
\end{tabular}

All of the students choosing to write on creation, evolution, and the second law started out by defending some form of theme 3 of the previous version of the assignment. Through the interaction between the proposal stage and the full paper stage of the assignment, these students were required to consider counter-arguments and to interact with supporters of evolution. One student encouraged the second author by setting out to defend a form of theme 2 but concluding as a result of his research and reflection that it was not as tenable as theme 1.

Tables 3 and 4 show that in 2003, students still rated thermodynamics as more related to the Christian faith than dynamics, and less related than ethics, though the latter difference was not statistically significant. 
The second law term paper assignment has become an established, successful feature in the engineering program at Geneva College. Two different instructors have incorporated the assignment into the Engineering Thermodynamics course taken by all engineering majors. This assignment is a good fit with the missions of the college and of the department, both in equipping students to "see their professions as a calling from God in which they may serve Him and in so doing may do good to others and have a transforming effect on society", and in integrating engineering and the liberal arts.

Students perceive a difference between this course and other technical courses, consistently rating it more related to the Christian faith, and the differences in perceptions are almost always statistically significant. These differences were measurable and repeatable even as instructors changed and the assignment evolved. Anecdotal evidence also suggests that the assignment helps students make connections between engineering and the liberal arts. This evidence ranges from references to Bible and Humanities lectures in the papers, to comments on course evaluation forms and ongoing student discussions outside of the classroom.

\section{Recommendations}

Since thermodynamics is at the core of most engineering curricula, and the second law provides a great amount of material for discussion, institutions with missions similar to Geneva College may find that they can adopt our approach with little change. The authors would be very interested in the results of such experiments, and are happy to share any information we can. As engineers, we can often become so focused on the technical content issues that we miss opportunities for learning that cuts across disciplinary boundaries. Our approach provides a working model of a process to break through those boundaries.

Institutions without a specifically religious mission may find that they can adapt the assignment by either reference to codes of ethics that address environmental issues such as that of the American Society of Civil Engineers through its ethical statement on sustainable development, for example, ${ }^{20}$ or by connection to social science/liberal arts applications of the second law. This could be done within the context of the mission statement of the university and/or the department in much the same way as we have done and would provide similar opportunities to connect the technical course to the liberal arts and to provide practice in writing and reasoning in a format different from typical engineering writing.

As a concrete example, the original assignment could be rephrased as follows.

Consider the development of technology in terms of entropy and the second law of thermodynamics. What are the increases in entropy (disorder) which come about to make up for the increases in order (for example, greater life expectancy and a higher standard of living) which the technology user experiences? 
In light of the ethical requirements of our university's mission statement, what do you believe to be a practical approach to the advance of technology and its effect on the entropy of the universe? Interact with opinions that both support and oppose your "practical approach."

How does or should this influence your career choice and professional activities? Give clear and specific examples of how the approach you have outlined does or could find application.

The reference to the university's mission statement in the second paragraph could be replaced with a reference to the statement on sustainable development in the ASCE code of ethics, or some other ethical standard.

\footnotetext{
${ }^{1}$ Manuel-Dupont, Sonia, "Writing-Across-the-Curriculum in an Engineering Program", J. Eng. Ed., vol. 85, no. 1, 1996, pp. 35-40.

${ }^{2}$ Ludlow, Douglas K. and Kirk H. Schulz, "Writing Across the Chemical Engineering Curriculum at the University of North Dakota", J. Eng. Ed., vol. 83, no. 2, 1994, pp. 161-68.

${ }^{3}$ Walker, Kristin, "Integrating Writing Instruction into Engineering Courses: A Writing Center Model", J. Eng. Ed., vol. 89, no. 3, 2000, pp. 369-376.

${ }^{4}$ Hawkins, Susan, Mary B. Coney, and Karl-Erik Bystrom, “Incidental Writing in the Engineering Classroom”, $J$. Eng. Ed., vol. 85, no. 1, 1996, pp. 27-35.

${ }^{5}$ Wheeler, Edward and Robert L. McDonald, "Writing in Engineering Courses", J. Eng. Ed., vol. 89, no. 4, 2000, pp. 481-486.

${ }^{6}$ Sharp, Julie E., Barbara M. Olds, Ronald L. Miller and Marilyn Dyrud, "Four Effective Writing Strategies for Engineering Classes", J. Eng. Ed., vol. 88, no. 1, 1999, pp. 53-58.

${ }^{7}$ Penn State University Home Page. 2002. Penn State University, Office of University Relations. January 7, 2004.

$<$ http://www.psu.edu/ur/about/mission.html $>$.

${ }^{8}$ Carnegie Mellon University Home Page. May 28, 1998. Carnegie Mellon University. January 7, 2004.

$<$ http://www.cmu.edu/splan/Mission.htm>.

${ }^{9}$ University of Utah Home Page. University of Utah. January 7, 2004.

$<$ http://www.admin.utah.edu/president/mission.html $>$.

${ }^{10}$ Nicholas Georgescu-Roegen, The Entropy Law and the Economic Process, Harvard University Press, Cambridge, MA, 1971.

${ }^{11}$ Accreditation Board for Engineering and Technology, Inc., Criteria for Accrediting Engineering Programs, Baltimore, MD, November, 2002, <http://www.abet.org/images/Criteria/E1 03-04 EAC Criteria 11-15-02.pdf>.

12 Rifkin, Jeremy and Ted Howard, Entropy: A New World View, The Viking Press, New York, 1980.

${ }^{13}$ De Vos, Peter, Calvin De Witt, Eugene Dykema, Vernon Ehlers, and Loren Wlkinson, Earthkeeping in the Nineties: Stewardship of Creation, Eerdmans, Grand Rapids, Michigan, 1991.

${ }^{14}$ Walpole, Ronald, and Myers, Raymond, Probability and Statistics for Engineers and Scientists, Macmillan, New York, 1972, pp. 249-254.

${ }^{15}$ Williams, Emmett L., "Creation Model of Natural Processes”, Thermodynamics and the Development of Order, ed. Emmett L. Williams, Creation Research Society Books, Norcross, Georgia, 1981, pp 116-117.

${ }^{16}$ Morris, Henry M., The Twilight of Evolution, Baker House Books, Grand Rapids, Michigan, 1963 , pp 33-48.

${ }^{17}$ Morris, Henry M., Scientific Creationism, Creation-Life Publishers, San Diego, 1974, p 212.

${ }^{18}$ North, Gary, Is the World Running Down? Crisis in the Christian Worldview, Institute for Christian Economics, Tyler, Texas, 1988, p 126.

${ }^{19}$ Armstrong, Harold L., David R. Boylan, Emmett L. Williams, and Duane T. Gish., "Development and Stability of Order", Thermodynamics and the Development of Order, ed. Emmett L. Williams, Creation Research Society Books, Norcross, Georgia, 1981, pp 23-110.

${ }^{20}$ American Society of Civil Engineers Home Page. November 10, 1996. American Society of Civil Engineers. January 13, 2004. < http://www.asce.org/inside/codeofethics.cfm>.
} 
DAVID SHAW is Professor of Mechanical Engineering at Geneva College. He received his B.S.M.E. from Geneva College and his M.S. and Ph.D. from the Ohio State University. His research interests include measurement and modeling of thermal properties of materials ranging from ash deposits to methane hydrate deposits. He has been active in sponsoring student teams in competitions such as Solar Splash.

JAMES GIDLEY is Professor of Civil Engineering at Geneva College. He received his B.S.C.E.E. from the University of Rhode Island and his S.M. and Ph.D. from Harvard University. His research interests include thermodynamic analysis of pipe networks and the interactions between technology and society. He is currently Chair of the Engineering Department at Geneva. 